\title{
EVALUASI KESESUAIAN LAHAN UNTUK TANAMAN JAGUNG DI KECAMATAN BINJAI UTARA
}

\author{
Julinar Veronika $S 1$, Elfayetti² \\ 'Alumnus S1 Jurusan Pendidikan Geografi Fakultas Ilmu Sosial Universitas Negeri Medan \\ 2Jurusan Pendidikan Geografi Fakultas Ilmu Sosial Universitas Negeri Medan \\ Jl. Willem Iskandar Psr V Medan Estate Medan, 20211 Indonesia \\ Email: julinarveronika@gmail.com
}

\begin{abstract}
Abstrak:
Penelitian ini bertujuan untuk mengetahui karakteristik lahan pertanian dilihat dari suhu, topografi, KTK, pH, N-total, P2O5, dan K2O untuk tanaman jagung yang ada di Kecamatan Binjai Utara. Penelitian ini dilakukan di Kecamatan Binjai Utara tahun 2016. Populasi dalam penelitian ini adalah seluruh areal yang ditanami tanaman jagung dengan luas 235 ha di Kecamatan Binjai Utara. Sampel ditentukan dengan Purposive Sampling (metode pengambilan sampel yang tidak bersifat acak). Dimana Sampel diambil berdasarkan satuan lahan yang diperoleh dari gabungan beberapa peta (overlay peta). Teknik pengumpulan data yang digunakan adalah teknik observasi, teknik pengukuran langsung dan dokumentasi. Data dianalisis secara deskriptif kualitatif. Hasil penelitian menunjukkan bahwa: (1) pada sampel tanah Kelurahan Jati Karya dengan KTK 16,36, pH 5,3, unsur Nitrogen 0,09\%, Posfor 5,75 ppm, Kalium 0,2 me/100gr. Sampel tanah Jati Utomo dengan KTK 13,38, pH 5,5, unsur Nitrogen 0,06\%, Posfor 6,25 ppm, Kalium 0,2 me/100gr. Sedangkan pada sampel tanah Cengkeh Turi dengan KTK 16,50, pH 6,3, unsur Nitrogen 0,08\%, Posfor 6,75 ppm, dan Kalium 0,2 me/100gr. (2) Kesesuaian lahan pada Kecamatan Binjai Utara menunjukkan kelas kesesuaian lahan N2 (tidak sesuai permanen).
\end{abstract}

\section{Kata kunci : Kesesuaian lahan, jagung, binjai utara}

\section{PENDAHULUAN}

Indonesia merupakan Negara Agraris yang sebagian besar penduduknya bekerja pada bidang pertanian, artinya pertanian memegang peranan penting pada perekonomian nasional, sehingga pembangunan pertanian meningkatkan pembangunan nasional. Walau termasuk sektor penting, namun sektor pertanian ini masih sangat kurang kontribusinya dalam pembangunan bangsa. Kurangnya perhatian yang serius dari pemerintah dan juga kurangnya pemahaman dari masyarakat dalam pengolahan lahan merupakan beberapa alasan yang menyebabkan hasil pertanian kurang bisa memberikan kontribusi yang baik bagi bangsa.

Indonesia merupakan tempat
tumbuh berbagai jenis tanaman horikultura. Horikultura secara etimologi berarti membudidayakan tanaman di kebun sehingga bersifat lebih intensif, padat modal dan tenaga kerja. (http://dasarhortikultura.wordpress.com/di akses23-april-2016). Salah satu jenis tanaman yang termasuk ke dalam tanaman hortikultura adalah jagung.

Sampai akhir tahun 2012 Indonesia belum berhasil mencapai keseimbangan dalam produksi jagung. Produksi jagung nasional sebenarnya sudah ada peningkatan, tetapi tidak sebanding dengan pertumbuhan tingkat konsumsi jagung nasional, sehingga pada tahun 2012 Indonesia masih harus melakukan impor jagung. Hasil produksi jagung secara standar nasional diperkirakan sekitar 10-12 ton. Pertanian jagung di Sumatera Utara merupakan komoditas nomor dua terbesar setelah komoditas beras dimana produksi jagung pada tahun 2010 dengan luas panen 274.822 ha menghasilkan produksi sebesar 1.377.718 ton. Dan pada tahun 
2011 luas panen menurun menjadi 255.291 ha dengan hasil produksi 1.294.645 ton (Dinas Pertanian Prov. Sumut, 2011). Kecamatan Binjai Utara adalah salah satu Kecamatan yang terdapat di Kota Binjai Provinsi Sumatera Utara, yang tanaman pangannya selain padi adalah jagung dan tanaman palawija. Kecamatan Binjai Utara adalah salah satu daerah yang memproduksi jagung di Kota Binjai. Pada tahun 2012 luas panen untuk tanaman jagung 392 ha dengan menghasilkan produksi 2.438 ton, pada tahun 2013 luas menurun menjadi 235 ha dengan produksi 1.469 ton ( Kecamatan Binjai Utara Dalam Angka 2014) dan tentunya masih jauh dari standar pertanian nasional.

Tanaman jagung berasal dari daerah tropis yang dapat menyesuaikan diri dengan lingkungan di luar daerah tersebut. Jagung tidak menuntut persyaratan lingkungan yang terlalu ketat, dapat tumbuh pada berbagai macam tanah bahkan pada kondisi tanah yanag agak kering. Tetapi untuk pertumbuhan optimalnya, jagung menghendaki beberapa persyaratan. Jagung dapat tumbuh di daerah yang terletak antara 0-50 derajat LU hingga 0-40 derajat LS. Suhu yang dikehendaki tanaman jagung antara 21-34 derajat Celcius, akan tetapi bagi pertumbuhan tanaman yang ideal memerlukan suhu optimum antara 23-27 derajat Celcius. Pada proses perkecambahan benih jagung memerlukan suhu yang cocok sekitar 30 derajat Celcius.

Perkembangan kebutuhan jagung sangat jauh di atas kemampuan produksi dalam negeri. Namun upaya dalam peningkatan produksi jagung masih banyak mengalami hambatan antara lain masih rendahnya rata-rata produksi per hektar, belum menggunakan varietas jagung yang unggul, penanaman jagung belum dilakukan pada lahan yang sesuai dengan kriteria persyaratan tumbuh tanaman jagung. Dalam hal ini informasi keadaan tanah sangat diperlukan agar produktivitas lahan untuk tanaman jagung dapat ditingkatkan.
Produksi tanaman jagung dipengaruhi oleh kondisi fisik dan non fisik. Pemerintah lebih terfokus untuk melakukan usaha-usaha yang berkaitan dengan kondisi non fisik meliputi seperti penyuluhan, pemberian bibit unggul dan sebagainya. Padahal untuk mengefisienkan berbagai usaha yang telah dirintis pemerintah tersebut dibutuhkan data-data tentang kondisi karakteristik lahan karena setiap lahan memiliki karakteristik yang berbedabeda, baik dari jenis tanah, $\mathrm{pH}$, ketersediaan unsur hara dan lain-lain. Cara untuk mendapatkan data karakteristik lahan yang bisa dilakukan adalah dengan evaluasi lahan.

Untuk mendapatkan data-data tentang karakteristik lahan, maka diperlukan suatu evaluasi sumberdaya lahan untuk tanaman jagung tersebut. Menurut Sitorus (1985) evaluasi kesesuaian lahan pada hakikatnya berhubungan dengan evaluasi untuk satu penggunaan lahan tertentu, seperti untuk budidaya padi, jagung dan sebagainya. Fungsi evaluasi sumber daya lahan adalah memberikan pengertian tentang hubunganhubungan antara kondisi lahan dan penggunaannya serta memberikan kepada perencana berbagai perbandingan dan alternatif pilihan penggunaan yang dapat diharapkan berhasil.

Satu komponen penting yang mempengaruhi produksi tanaman adalah tanah. Tanah merupakan media tumbuh alami untuk tanaman. Lahan pertanian yang digunakan secara terus menerus untuk pertanaman tanaman pangan dapat menurunkan kualitas tanah dan produktivitas apabila tidak menerapkan teknik konservasi tanah dan air yang memadai. Menurut Arsyad (2006) upaya konservasi tanah dan air ditujukan untuk mencegah erosi, memperbaiki tanah yang rusak, dan memelihara, serta meningkatkan prosuktivitas tanah agar tanah dapat digunakan secara berkelanjutan (lestari). Penggunaan pupuk kimia yang berlebihan dapat menurunkan kondisi fisik, kimia, dan biologi tanah, sehingga tanah menjadi 
kurang subur dan produksi tanaman dapat menurun.

Tanah memiliki 2 sifat utama, yaitu sifat fisik dan sifat kimia tanah. Sifat fisik tanah ini sangat penting di tinjau dari pengolahan dan pengelolaannya, dari warna,tekstur,struktur dan drainase. Di dalam tanah terjadi berbagai reaksi kimia karena tanah memiliki unsur-unsur kimia yang terlarut di dalam air. Karena reaksi kimia tersebut, nutrisi yang ada di dalam tanah dapat mudah diserap oleh tanaman. Namun apabila kondisi tanah tidak baik seperti miskin unsur hara yang terlalu tinggi atau terlalu rendah ini akan mempengaruhi pertumbuhan tanaman.

Dengan dilakukannya evaluasi kesesuaian lahan maka, diharapkan akan diperoleh data-data karakteristik lahan yang akan menunjukkan sifat-sifat lahan yang pada akhirnya akan diketahui tingkat kesesuaian lahan terhadap tanaman jagung. Sehingga, dapat dilakukan usahausaha yang sesuai dengan karakteristik lahan yang pada akhirnya akan mengoptimalkan produksi tanaman yang dalam penelitian ini adalah tanaman jagung.

Berdasarkan latar belakang masalah yang telah dipaparkan maka dapat diidentifikasi permasalahan yang ada di Kecamatan Binjai Utara yaitu sebagai berikut : (1) Produksi tanaman jagung di Kecamatan Binjai Utara masih di bawah standar nasional; (2) Peranan pemerintah masih lebih terfokus untuk melakukan usaha-usaha yang berkaitan dengan unsur non fisik seperti penyuluhan dan pemberian bibit unggul; (3) perlunya evaluasi lahan untuk mengetahui karakteristik dan tingkat kesesuaian lahan terhadap tanaman jagung di Kecamatan Binjai Utara.

\section{METODE PENELITIAN}

Penelitian ini dilakukan di Kecamatan Binjai Utara. Adapun alasan dari peneliti memilih lokasi ini adalah :

1. Untuk mengetahui tingkat kesesuian lahan pertanian untuk tanaman jagung dikarenakan hasilnya yang masih di bawah standar pertanian nasional.

2. Sepengetahuan penulis, belum pernah dilakukan penelitian yang sejenis di daerah ini.

Populasi dari penelitian ini adalah seluruh areal tanah yang ditanami tanaman jagung dengan luas 235 ha di Kecamatan Binjai Utara, maka yang akan dijadikan sampel pada penelitian ini adalah dengan metode pengambilan sampel purposive sampling (metode pengambilan sampel yang tidak bersifat acak). Dimana sampel diambil berdasarkan satuan lahan yang diperoleh dari gabungan beberapa peta (overlay peta) seperti peta jenis tanah, peta ketinggian tempat dan peta penggunaan lahan, maka terdapat 3 titik sampel yaitu kelurahan jati karya, jati utomo dan cengkeh turi. Variabel dalam penelitian ini terdiri dari karakteristik lahan yaitu suhu, topografi, KTK, pH, N-total, $\mathrm{P} 2 \mathrm{O} 5$, dan $\mathrm{K} 2 \mathrm{O}$.

Teknik pengumpulan data dalam penelitian ini adalah :

\section{Observasi}

Teknik pengumpulan data dalam penelitian ini adalah melakukan pengamatan sampel langsung di lapangan.

2. Teknik Pengukuran Langsung

Teknik pengumpulan data dalam penelitian ini juga dilakukan dengan teknik pengukuran langsung. Alat yang dapat digunakan dalam teknik ini adalah:

a. Meteran yaitu alat yang digunakan untuk mengukur jarak atau panjang blok pengamatan penelitian.

b. GPS adalah alat yang digunakan untuk mengetahui letak kordinat dan ketinggian tempat daerah penelitian.

c. Cangkul adalah alat yang yang digunakan untuk pengambilan sampel tanah. 
d. Kantung plastik yaitu alat untuk tempat penyimpanan sampel tanah.

e. Alat-alat tulis yaitu alat alat yang digunakan untuk menulis laporan pengamatan di lapangan.

3. Studi Dokumentasi

$\begin{array}{llr}\text { Teknik ini digunakan untuk } \\ \text { melengkapi } & \begin{array}{l}\text { data-data yang } \\ \text { data }\end{array}\end{array}$ berhubungan dengan penelitian dari instansi pemerintahan seperti dinas pertanian dan dinas perkebunan.

Pengambilan data yang dilakukan adalah dengan melakukan pengeboran tanah. Pengeboran tanah dilakukan dengan bor tanah atau sejenisnya yang dapat digunakan untuk membor tanah. Tujuannya untuk melihat kedalaman perakaran dan keadaan drainase tanah. Selanjutnya tanah diambil kira-kira sebanyak $1 \mathrm{~kg}$ dimasukkan ke dalam kantung plastik. Tanah yang diambil tidak bisa langsung terkena sinar matahari dalam proses pengeringannya untuk menghindari hilangnya unsur yang terkandung dalam tanah. Selanjutnya tanah dibawa untuk dilakukan uji laboratorium yang gunanya untuk mengetahui $\mathrm{N}$-total, P2O5, K2O tersedia, KTK me/100gr tanah (subsoil),

Teknik analisis data dalam penelitian ini adalah dengan menggunakan teknik deskriptif Kualitatif. Data yang diperoleh dari lokasi penelitian ditulis dalam bentuk laporan terperinci dan sampel tanah yang diperoleh dari lokasi penelitian di uji ke laboratorium guna melihat $\mathrm{KTK}, \mathrm{pH}, \mathrm{N}$-total, $\mathrm{P} 2 \mathrm{O} 5$, dan $\mathrm{K} 2 \mathrm{O}$. Kemudian karakteristik lahan yang ada dicocokkan (matching) dengan kriteria kesesuaian tanaman jagung.

\section{HASIL DAN PEMBAHASAN}

\section{Karakteristik Lahan Pertanian Di Kecamatan Binjai Utara}

Tanah mempunyai sifat yang sangat kompleks, terdiri atas komponen yang berinteraksi dengan cairan, dan udara. Komponen pembentuk tanah yang berupa padatan, cair, dan udara jarang berada dalam kondisi ketidakseimbangan, selalu berubah mengikuti perubahan yang terjadi di atas permukaan tanah yang dipengaruhi oleh suhu, udara, angin, dan sinar matahari. Untuk bidang pertanian, tanah merupakan media tumbuh tanaman. Media yang baik bagi pertumbuhan tanaman harus mampu menyediakan kebutuhan tanaman seperti air, udara, unsur hara, dan terbebas dari bahan-bahan beracun dengan konsentrasi yang berlebihan.

Lahan pertanian yang ada di Kecamatan Binjai Utara sangat dipengaruhi oleh faktor cuaca dan iklim juga curah hujan. Pada musim penghujan, petani menanam padi pada lahan sawah, sedangkan pada musim kemarau para petani menanam sayuran dan tanaman lainnya.

Lokasi penelitian ini terletak di Kecamatan Binjai Utara dengan luas wilayah sekitar $23,59 \mathrm{~km}^{2}$ dan memiliki tanaman jagung sebesar 235 ha. Berdasarkan topografi Kecamatan Binjai Utara terletak pada koordinat $3^{\circ} 31^{\prime} 40^{\prime \prime}$ 3० 40 2" LU dan 98०27' 3" - 98॰ 32' 32" BT, berada pada ketinggian sekitar 30 meter dari permukaan laut, dengan temperatur suhu antara $30^{\circ} \mathrm{C}-32^{\circ} \mathrm{C}$, iklim tropis dipengaruhi oleh musim hujan dan musim kemarau dengan curah hujan rata-rata 21026 mm. (Kantor Camat Binjai Utara Dalam Angka, 2015)

Data sampel diambil berdasarkan satuan lahan dengan menggunakan peta yang di overlay dari peta penggunaan lahan, peta jenis tanah, dan peta kemiringan lereng. Dari hasil penelitian di lapangan oleh peneliti di ketiga kelurahan yang merupakan lokasi penelitian. Jenis tanah yang terdapat di daerah penelitian ada 2 jenis yaitu alluvial dan fluvial. Tanah aluvial/tanah endapan adalah tanah yang dibentuk dari lumpur sungai yang mengendap di dataran rendah yang memiliki sifat tanah yang subur dan cocok untuk lahan pertanian.Tanah Alluvial berwarna kelabu muda bersifat fisik keras dan pijal jika kering dan lekat jika basah. 
Kaya akan fosfat yang mudah larut dalam sitrat 2\% mengandung 5\% CO2 dan tepung kapur yang halus dan juga berstruktur pejal yang dalam keadaan kering dapat pecah menjadi fragmen berbetuk persegi sedang sifat kimiawinya sama dengan bahan asalnya.

Tekstur tanahnya liat atau liat berpasir, mempunyai konsistensi keras waktu kering dan teguh pada waktu lembab. Kandungan unsur haranya relatif kaya dan banyak tergantung pada bahan induknya. Reaksi tanahnya dari asam, netral sampai basa. Berdasarkan bahan induknya terdapat tanah Aluvial pasir, lempung, kapur, basa,asam dan lain-lain.

Untuk melihat hasil penelitian yang telah dilakukan maka dapat dilihat sebagai berikut.

a. Suhu

Untuk kecamatan Binjai Utara suhu rata-ratanya adalah $30^{\circ}-32^{\circ} \mathrm{C}$. Tentu saja yang menjadi salah satu syarat tumbuh tanaman jagung dalam penentuan kelas kesesuaian lahan tanaman jagung adalah suhu/temperatur. Temperatur juga menjadi pembatas yang nyata dalam batas pertumbuhan tanaman. Rata-rata curah hujan tahunan dari tahun 2006-2015 adalah $21026 \mathrm{~mm}$. Suhu yang dikehendaki tanaman jagung untuk pertumbuhan terbaiknya antara $20-26^{\circ} \mathrm{C}$. Pada proses perkecambahan benih, jagung memerlukan suhu berkisar $30^{\circ} \mathrm{C}$. Rata-rata suhu yang diperlukan tanaman jagung berkisar 20$22^{\circ} \mathrm{C}$ untuk lahan $\mathrm{S1}, 23-25^{\circ} \mathrm{C}$ untuk lahan S2, $26-30^{\circ} \mathrm{C}$ untuk lahan S3, 31-32 untuk lahan N1 dan > 32 untuk lahan N2.

\section{b. Topografi}

Kemiringan atau topografi di lokasi penelitian memiliki kemiringan lereng 0 $15 \%$ dan ketinggian tempat lokasi penelitian yaitu 30mdpl. Ketinggian tempat yang optimum untuk tanaman jagung adalah 0-600mdpl untuk lahan S1, $>600-1800$ untuk lahan $52,>1800$ untuk lahan S3.

\section{c. Daya menahan unsur hara (f)}

Dalam daya menahan unsur hara terdapat 2 hal yang dilihat yaitu KTK dan reaksi tanah atau $\mathrm{pH}$ tanah. Kandungan KTK (Kapasitas Tukar Kation) yang terdapat di daerah penelitian pada tiga lokasi pengambilan sampel berkisar di antara 13-16 me/100gr.

Tabel 1. Kondisi KTK Pada Tanaman Jagung Di Kecamatan Binjai Utara Tahun

\begin{tabular}{|c|c|c|c|}
\hline No & Sampel & $\begin{array}{c}\text { KTK } \\
\text { (me/100gr) }\end{array}$ & Keterangan \\
\hline 1 & A & 16,36 & Rendah \\
2 & B & 13,38 & Rendah \\
3 & C & 16,50 & Rendah \\
\hline
\end{tabular}

Sumber: Data Primer Olahan, 2016

Sesuai dengan tabel 1 diatas dapat disimpulkan bahwa pada ketiga sampel tanah diatas seluruhnya bersifat rendah karena KTK nya di bawah 16,50 me/100gr. KTK yang optimum untuk tanaman jagung yaitu $>40$ untuk lahan S1, 39-24 untuk lahan S2, 23-16 untuk lahan S3, 15-5 untuk lahan N1 dan <4 untuk lahan N2.

Tabel 2. Kondisi pH Pada Tanaman Jagung di Kecamatan Binjai Utara Tahun 2016

\begin{tabular}{|c|c|c|c|}
\hline No & Sampel & $\mathrm{pH}$ & Keterangan \\
\hline 1 & $\mathrm{~A}$ & 5,3 & Asam \\
2 & $\mathrm{~B}$ & 5,5 & Asam \\
3 & $\mathrm{C}$ & 6,3 & Agam asam \\
\hline
\end{tabular}

Sumber: Data Primer Olahan, 2016

Sesuai dengan tabel 2 diatas dapat disimpulkan bahwa dari ketiga sampel tanah diatas seluruhnya bersifat agak asam karena $\mathrm{pH}$ nya di bawah 6,5. $\mathrm{pH}$ tanah yang optimum untuk tanaman jagung yaitu 4,5-5,2 untuk lahan $S 1,5,3-5,6$ untuk lahan S2, 5,7-6,7 untuk lahan $\$ 3,6,8-8,2$ untuk lahan $\mathrm{N} 1$ dan $>8,3$ untuk lahan N2.

d. Ketersediaan unsur hara (n)

Untuk melihat karakteristik dalam ketersediaan unsur hara didalam tanah dapat dilihat melalui unsur Nitrogen, $\mathrm{P}_{2} \mathrm{O}_{5}$ dan $\mathrm{K}_{2} \mathrm{O}$. Berdasarkan hasil laboratorium 
dari sampel lapangan menunjukkan sebagai berikut :

Tabel 3. Kadar Nitrogen Total Pada Sampel Tanah Tanaman Jagung di Kecamatan Binjai Utara Tahun 2016

\begin{tabular}{|c|c|c|c|}
\hline No & Sampel & $\begin{array}{c}\text { N-Total } \\
(\%)\end{array}$ & Keterangan \\
\hline 1 & A & 0,09 & Sangat rendah \\
2 & B & 0,06 & Sangat rendah \\
3 & C & 0,08 & Sangat rendah \\
\hline
\end{tabular}

Sumber: Data Primer Olahan, 2016

Sesuai dengan tabel 3 diatas dapat disimpulkan bahwa dari ketiga sampel tanah diatas seluruhnya kandungan unsur $\mathrm{N}$-total di daerah penelitian berkisar 0,06\%-0,09\% yang berarti kandungan unsur $\mathrm{N}$ berada pada kelas sangat rendah. Nitrogen yang optimum untuk tanaman jagung yaitu $>0,75$ untuk lahan S1, 0,740,50 untuk lahan $\$ 2,0,49-0,20$ untuk lahan S3, 0,19-0,10 untuk lahan N1 dan $<0,09$ untuk lahan N2.

Untuk ketersediaan unsur $\mathrm{P}_{2} \mathrm{O}_{5}$ yang terdapat dilapangan sesuai dengan hasil laboratorium adalah berkisar $5-7$ ppm yang menandakan bahwa unsur $\mathrm{P}$ di lokasi penelitian berada di tingkat rendah.

Tabel 4. Kadar $\mathrm{P}_{2} \mathrm{O}_{5}$ Pada Sampel Tanah

Tanaman Jagung di Kecamatan Binjai Utara Tahun 2016

\begin{tabular}{|c|c|c|c|}
\hline No & Sampel & P (ppm) & Keterangan \\
\hline 1 & A & 5,75 & Rendah \\
2 & B & 6,25 & Rendah \\
3 & C & 6,75 & Rendah \\
\hline
\end{tabular}

Sumber: Data Primer Olahan, 2016

Sesuai dengan tabel 4 dapat disimpulkan bahwa dari ketiga sampel tanah diatas berada pada kelas rendah. $\mathrm{P}_{2} \mathrm{O}_{5}$ yang optimum untuk tanaman jagung yaitu $>35$ untuk lahan S1, 34-30 untuk lahan S2, 29-20 untuk lahan S3, 19-11 untuk lahan N1 dan <10 untuk lahan N2.

Dan untuk ketersediaan unsur $\mathrm{K}_{2} \mathrm{O}$ di lokasi penelitian berkisar 0,2me/100gr dan termasuk ke dalam kelas pembatas sangat rendah.

Tabel 5. Kadar Kalium Pada Sampel Tanah

Tanaman Jagung di Kecamatan Binjai Utara Tahun 2016

\begin{tabular}{|c|c|c|c|}
\hline No & Sampel & $\begin{array}{c}\text { Kalium } \\
\text { (mg/100gr) }\end{array}$ & Keterangan \\
\hline 1 & A & 0,2 & $\begin{array}{c}\text { Sangat } \\
\text { rendah } \\
\text { Sangat } \\
\text { rendah } \\
\text { Sangat } \\
\text { rendah }\end{array}$ \\
\hline
\end{tabular}

Sumber: Data Primer Olahan, 2016

Sesuai dengan tabel 5 dapat disimpulkan bahwa ketiga sampel tanah diatas berada pada kelas sangat rendah. $\mathrm{K}_{2} \mathrm{O}$ yang optimum untuk tanaman jagung yaitu $>60$ untuk lahan S1, 59-40 untuk lahan S2, 39-20 untuk lahan S3, 19-11 untuk lahan N1, dan $<10$ untuk lahan N2.

Tabel 6. Karakteristik dan Kualitas Lahan Pada Lokasi Titik Sampel

\begin{tabular}{|c|c|c|c|}
\hline \multirow{2}{*}{ Kualitas / Karakteristik Lahan } & \multicolumn{3}{|c|}{ Satuan Lahan } \\
\cline { 2 - 4 } & $\mathrm{A}$ & $\mathrm{B}$ & $\mathrm{C}$ \\
\hline Temperatur & & & \\
- Temperatur rerata $\left({ }^{\circ} \mathrm{C}\right)$ & $31{ }^{\circ} \mathrm{C}$ & $31{ }^{\circ} \mathrm{C}$ & $31{ }^{\circ} \mathrm{C}$ \\
\hline - $\mathrm{KTK}(\mathrm{me} / 100 \mathrm{gr})$ & 16,36 & 13,38 & 16,50 \\
- $\mathrm{pH}$ & 5,3 & 5,5 & 6,3 \\
\hline - $\mathrm{N}$-total (\%) & 0,09 & 0,06 & 0,08 \\
- $\mathrm{P}_{2} \mathrm{O}_{5}$ tersedia(ppm) & 5,75 & 6,25 & 6,75 \\
$-\mathrm{K}_{2} \mathrm{O}$ tersedia (me/100gr) & 0,2 & 0,2 & 0,2 \\
\hline
\end{tabular}




\begin{tabular}{|c|c|c|c|}
\hline topografi & & & \\
$-\quad$ Kemiringan lereng (\%) & $15 \%$ & $15 \%$ & $15 \%$ \\
$-\quad$ Ketinggian tempat (mdpl) & $30 \mathrm{mdpl}$ & $30 \mathrm{mdpl}$ & $30 \mathrm{mdpl}$ \\
\hline
\end{tabular}

Sumber : Data Primer Olahan, 2016

Data dari tabel 6 berikut di dapat berdasarkan observasi di lapangan dan juga hasil laboratorium dari sampel yang diperoleh pada lokasi penelitian dan dari tabel berikut data dapat diidentifikasi mengenai karakteristik lahan.

Untuk memperoleh kelas kesesuaian lahan diperlukan data mengenai kualitas lahan dan karakteristik lahan. Karakteristik lahan merupakan suatu sifat lahan yang dapat diukur, sedangkan kualitas lahan adalah suatu sifat kompleks dari lahan yang nyata perbedaannya dalam mempengaruhi tingkat kesesuaian lahan untuk suatu bentuk penggunaan lahan. Karakteristik atau yang disebut juga dengan ciri-ciri lahan merupakan indikator atau ciri-ciri yang menunjukkan kualitas lahan. Untuk menentukan kelas kesesuaian lahan maka yang digunakan adalah karakteristik lahan/ciri lahan.

Dalam evaluasi kesesuaian lahan dikenal pembatas yang dapat diperbaiki dan pembatas yang tidak diperbaiki. Regim temperatur merupakan salah satu pembatas yang tidak dapat diperbaiki sehingga apabila regim temperatur tidak sesuai dengan suatu jenis tanaman, maka tidak dapat dilakukan perbaikan terhadap lahan. Karakteristik lahan menjadi parameter regim temperatur adalah ratarata tahunan, bulan kering dan rata-rata curah hujan tambahan. Regim yang dimaksud adalah kondisi suhu secara terus menerus.

Suhu di daerah penelitian Kecamatan Binjai Utara adalah $31^{\circ} \mathrm{C}$. sedangkan untuk syarat untuk tumbuh tanaman jagung diperlukan $20-22^{\circ} \mathrm{C}$ maka suhu syarat tumbuh tanaman jagung tidak terpenuhi dalam penelitian ini. Karakteristik lahan yang menjadi parameter lain untuk regim temperatur adalah jumlah bulan basah, bulan kering dan rata-rata curah hujan tahunan. Untuk tanaman jagung suhu berada pada tingkat kesesuaian N1 yang berarti tidak sesuai untuk saat ini.

Daya menahan unsur hara merupakan kemampuan untuk menjaga agar unsur hara yang ada ditanah tidak larut dalam proses infiltrasi yang terjadi didalam tanah. Semakin tingginya daya unsur hara, maka kebutuhan tanaman terhadap hara tanah terpenuhi. Daya unsur hara terdiri dari KTK dan $\mathrm{pH}$ tanah. KTK merupakan sifat kimia tanah yang berhubungan erat dengan kesuburan tanah. Tanah yang memiliki nilai KTK tinggi mampu menyerap dan menyediakan unsur hara lebih baik dari pada tanah dengan KTK rendah. Berdasarkan hasil uji laboratorium KTK pada daerah penelitian rendah dan berada pada kelas kesesuaian lahan S3 yang berarti sesuai untuk marjinal.

$\mathrm{pH}$ tanah adalah yang berkaitan dengan tingkat keasaman tanah. Nilai $\mathrm{pH}$ di daerah penelitian yang berkisar 5,3 6,3 merupakan indikator asam sampai agak asam. Kandungan $\mathrm{pH}$ tanah berpengaruh pada pertumbuhan tanaman dan pemberian pupuk. $\mathrm{pH}$ tanah pada daerah penelitian berada pada kelas $\$ 2$ yang berarti cukup sesuai.

Ketersediaan unsur hara pada tanaman sangat penting bagi pertumbuhan tanaman agar dapat tumbuh secara optimal. Unsur hara yang dibutuhkan tanaman dibagi menjadi dua yaitu unsur makro dan unsur mikro. Unsur makro adalah unsur yang dibutuhkan tanaman dalam jumlah banyak dan unsur mikro adalah unsur yang dibutuhkan tanaman berjumlah sedikit. Seperti yang telah dibahas bahwa unsur yang dipertimbangkan adalah Nitrogen total, posfor tersedia dan potasium tersedia $(\mathrm{N}$ $\mathrm{P}-\mathrm{K})$. Untuk daerah penelitian berdasarkan 
analisis laboratorium diperoleh kandungan $\mathrm{N}$ berkisar 0,08 - 0,09 (sangat rendah) berada pada kelas S3 sesuai marginal. Unsur P 5,75 - 6,75 (rendah) berada pada kelas $N$ (tidak sesuai). Untuk unsur $\mathrm{K} 0,02$ yang artinya kandungannya (sangat rendah) berada pada kelas N2 yang berarti tidak sesuai permanen. Untuk mengatasi hal ini dapat ditingkatkan dengan pemberian pupuk yang baik untuk tanaman jagung.

Kualitas lahan yang terakhir adalah keadaan medan yang terdiri dari beberapa karakteristik lahan yaitu kemiringan lereng dan ketinggian tempat. Secara umum, Kecamatan Binjai Utara memiliki kemiringan lereng $15 \%$ berada pada kelas S3 (sesuai marjinal). Ketinggian tempat berada pada 30 mdpl yang berarti berada pada kelas 51 .

\section{Tingkat Kesesuaian Lahan Untuk Tanaman Jagung}

Dari hasil identifikasi yang diperoleh mengenai karakteristik lahan pada lokasi titik sampel penelitian. Hal selanjutnya yang akan dilakukan adalah mencocokkan data dari karakteristik lahan yang diperoleh dilapangan dengan data dari syarat tumbuh tanaman jagung (teknik matching). Dengan menggunakan teknik ini maka akan diketahui klasifikasi kesesuaian tanaman jagung pada titi sampel di lokasi penelitian. Hasil analisis data dengan teknik matching (pencocokkan) pada setiap titik sampel dapat dilihat pada tabel-tabel berikut.

a. Lokasi A

Setelah melakukan observasi lapangan guna mengumpulkan data yang berasal dari lapangan dan juga hasil dari laboratorium dan sampel yang dibawa dari lokasi penelitian diperoleh data sebagai berikut.

Tabel 7. Tingkat Kesesuaian Lahan Tanaman Jagung Pada Lokasi A

\begin{tabular}{|c|c|c|c|}
\hline \multirow[b]{2}{*}{ Kualitas Karakteristik Lahan } & Satuan Lahan & \multirow{2}{*}{$\begin{array}{l}\text { Syarat Tumbuh } \\
\text { Tanaman } \\
\text { Jagung }\end{array}$} & \multirow{2}{*}{$\begin{array}{c}\text { Kelas Kesesuaian } \\
\text { Lahan }\end{array}$} \\
\hline & A & & \\
\hline \multicolumn{4}{|l|}{ Temperatur } \\
\hline $\begin{array}{lll}\text { - } & \text { Temperatur } \\
& \text { tahunan }\left({ }^{\circ} \mathrm{C}\right) & \\
\end{array}$ & $31^{\circ} \mathrm{C}$ & $20-22^{\circ} \mathrm{C}$ & N1 \\
\hline $\begin{array}{ll}- & \text { KTK (me/100gr) } \\
\text { - } & \mathrm{Ph}\end{array}$ & $\begin{array}{c}16,36 \\
5,3\end{array}$ & $\begin{array}{c}>40 \\
4,5-5,2\end{array}$ & $\begin{array}{l}\text { S3 } \\
\text { S2 }\end{array}$ \\
\hline $\begin{array}{ll}- & \mathrm{N} \text {-total }(\%) \\
- & \mathrm{P}_{2} \mathrm{O}_{5} \text { tersedia }(\mathrm{ppm}) \\
- & \mathrm{K}_{2} \mathrm{O} \text { tersedia }(\mathrm{mg} / 100 \mathrm{gr})\end{array}$ & $\begin{array}{c}0,09 \\
5,75 \\
0,2\end{array}$ & $\begin{array}{l}>0,75 \\
>35 \\
>60\end{array}$ & $\begin{array}{l}\text { N2 } \\
\text { N2 } \\
\text { N2 }\end{array}$ \\
\hline $\begin{aligned} & \text { Topografi } \\
&- \text { Kemiringan lereng }(\%) \\
&- \text { Ketinggian tempat (mdpl) }\end{aligned}$ & $\begin{array}{c}15 \% \\
30 \mathrm{mdpl}\end{array}$ & $\begin{array}{c}0-3 \\
0-600\end{array}$ & $\begin{array}{l}\text { S3 } \\
\text { S1 }\end{array}$ \\
\hline Kelas Kesesuaian Lahan & & ง1 & $\begin{array}{l}\text { Tidak Sesuai } \\
\text { Untuk Saat Ini. }\end{array}$ \\
\hline
\end{tabular}

Sumber : Data Primer Olahan, 2016

Dari tabel 7 yang termasuk ke dalam faktor pembatasnya adalah Temperatur dan termasuk ke dalam kelas kesesuaian lahan N1 (tidak untuk saat ini) dengan faktor pembatas yang sangat berat.

b. Lokasi B
Setelah melakukan observasi lapangan guna mengumpulkan data yang berasal dari lapangan dan juga hasil dari laboratorium dan sampel yang dibawa dari lokasi penelitian diperoleh data sebagai berikut. 
Tabel 8. Tingkat Kesesuaian Lahan Tanaman Jagung Pada Lokasi B

\begin{tabular}{|c|c|c|c|}
\hline Kualitas Karakteristik Lahan & $\begin{array}{c}\begin{array}{c}\text { Satuan } \\
\text { Lahan }\end{array} \\
\text { B }\end{array}$ & $\begin{array}{l}\text { Syarat Tumbuh } \\
\text { Tanaman } \\
\text { Jagung }\end{array}$ & $\begin{array}{l}\text { Kelas } \\
\text { Kesesuaian } \\
\text { Lahan }\end{array}$ \\
\hline $\begin{array}{l}\text { Temperatur } \\
\text { - Temperatur rata-rata tahunan }\left({ }^{\circ} \mathrm{C}\right)\end{array}$ & $31^{\circ} \mathrm{C}$ & $20-22^{\circ} \mathrm{C}$ & N1 \\
\hline $\begin{array}{ll}- & \text { KTK (me/100gr) } \\
\text { - } & \mathrm{pH}\end{array}$ & $\begin{array}{c}13,38 \\
5,5\end{array}$ & $\begin{array}{l}>40 \\
4,5-5,2\end{array}$ & $\begin{array}{l}\text { N1 } \\
\text { S2 }\end{array}$ \\
\hline $\begin{array}{ll}- & \mathrm{N} \text {-total }(\%) \\
- & \mathrm{P}_{2} \mathrm{O}_{5} \text { tersedia }(\mathrm{ppm}) \\
- & \mathrm{K}_{2} \mathrm{O} \text { tersedia }(\mathrm{mg} / 100 \mathrm{gr})\end{array}$ & $\begin{array}{c}0,06 \\
6,25 \\
0,2\end{array}$ & $\begin{array}{l}>0,75 \\
>35 \\
>60\end{array}$ & $\begin{array}{l}\text { N2 } \\
\text { N2 } \\
\text { N2 }\end{array}$ \\
\hline $\begin{array}{ll}\text { Topografi } \\
-\quad \text { Kemiringan lereng }(\%) \\
-\quad \text { Ketinggian tempat (mdpl) }\end{array}$ & $\begin{array}{c}15 \% \\
30 \mathrm{mdpl}\end{array}$ & $\begin{array}{c}0-3 \\
0-600\end{array}$ & $\begin{array}{l}\text { S3 } \\
\text { S1 }\end{array}$ \\
\hline Kelas Kesesuaian Lahan & & N1 & $\begin{array}{l}\text { Tidak Sesuai } \\
\text { Untuk Saat Ini. }\end{array}$ \\
\hline
\end{tabular}

Sumber : Data Primer Olahan, 2016

Dari tabel 8 yang termasuk ke dalam faktor pembatasnya adalah Temperatur dan termasuk ke dalam kelas kesesuaian lahan N1 (tidak untuk saat ini) dengan faktor pembatas yang sangat berat.

c. Lokasi C
Setelah melakukan observasi lapangan guna mengumpulkan data yang berasal dari lapangan dan juga hasil dari laboratorium dan sampel yang dibawa dari lokasi penelitian diperoleh data sebagai berikut.

Tabel 9. Tingkat Kesesuaian Lahan Tanaman Jagung Pada Lokasi C

\begin{tabular}{|c|c|c|c|}
\hline \multirow[b]{2}{*}{ Kualitas Karakteristik Lahan } & Satuan Lahan & \multirow{2}{*}{$\begin{array}{l}\text { Syarat Tumbuh } \\
\text { Tanaman } \\
\text { Jagung }\end{array}$} & \multirow{2}{*}{$\begin{array}{l}\text { Kelas } \\
\text { Kesesuaian } \\
\text { Lahan }\end{array}$} \\
\hline & C & & \\
\hline $\begin{array}{l}\text { Temperatur } \\
\text { - Temperatur rata-rata tahunan }\left({ }^{\circ} \mathrm{C}\right)\end{array}$ & $31^{\circ} \mathrm{C}$ & $20-22^{\circ} \mathrm{C}$ & N1 \\
\hline $\begin{array}{ll}- & \text { KTK (me/100gr) } \\
- & \mathrm{pH}\end{array}$ & $\begin{array}{c}16,50 \\
6,3\end{array}$ & $\begin{array}{c}>40 \\
4,5-5,2\end{array}$ & $\begin{array}{l}\text { S3 } \\
\text { \$3 }\end{array}$ \\
\hline $\begin{array}{ll}- & \mathrm{N} \text {-total }(\%) \\
- & \mathrm{P}_{2} \mathrm{O}_{5} \text { tersedia }(\mathrm{ppm}) \\
- & \mathrm{K}_{2} \mathrm{O} \text { tersedia }(\mathrm{mg} / 100 \mathrm{gr})\end{array}$ & $\begin{array}{c}0,08 \\
6,75 \\
0,2\end{array}$ & $\begin{array}{l}>0,75 \\
>35 \\
>60\end{array}$ & $\begin{array}{l}\text { N2 } \\
\text { N2 } \\
\text { N2 }\end{array}$ \\
\hline $\begin{aligned} & \text { Topografi } \\
&- \text { Kemiringan lereng }(\%) \\
&- \text { Ketinggian tempat (mdpl) }\end{aligned}$ & $\begin{array}{c}15 \% \\
30 \mathrm{mdpl}\end{array}$ & $\begin{array}{c}0-3 \\
0-600\end{array}$ & $\begin{array}{l}\text { S3 } \\
\text { S1 }\end{array}$ \\
\hline Kelas Kesesuaian Lahan & & 11 & $\begin{array}{l}\text { Tidak Sesuai } \\
\text { Untuk Saat Ini. }\end{array}$ \\
\hline
\end{tabular}

Sumber : Data Primer Olahan, 2016

Dari tabel 9 yang termasuk ke dalam faktor pembatasnya adalah Temperatur dan termasuk ke dalam kelas kesesuaian lahan N1 (tidak sesuai untuk saat ini) dengan faktor pembatas yang sangat berat.
Dari ketiga tabel diatas, maka dapat disimpulkan bahwa tingkat kesesuaian lahan tanaman jagung di Kecamatan Binjai Utara terdiri dari kelas kesesuaian lahan N1 dengan luas 235 ha. 
Dalam hal faktor pembatas lahan juga dapat dilihat bahwa pembatas lahan yang berat dan tidak dapat diperbaiki pada tanaman jagung di Kecamatan Binjai Utara adalah temperatur, sementara yang dapat

Tabel 10. Klasifikasi Kelas Kesesuaian Lahan Pada Satuan Lahan

\begin{tabular}{|c|c|c|c|c|}
\hline \multirow{2}{*}{ Karakteristik lahan } & \multicolumn{3}{|c|}{ Satuan Lahan } & \multirow{2}{*}{ Kelas Kesesuaian Lahan } \\
\hline & $A$ & $B$ & $C$ & \\
\hline $\begin{array}{l}\text { Temperatur } \\
-\quad \text { Temperatur rata-rata tahunan }\left({ }^{\circ} \mathrm{C}\right)\end{array}$ & N1 & N1 & N1 & N1 \\
\hline $\begin{array}{ll}- & \mathrm{KTK}(\mathrm{me} / 100 \mathrm{gr}) \\
- & \mathrm{pH}\end{array}$ & $\begin{array}{l}\text { S3 } \\
\text { S2 }\end{array}$ & $\begin{array}{l}\mathrm{N} 1 \\
\mathrm{~S} 2\end{array}$ & $\begin{array}{l}\text { S3 } \\
\text { S3 }\end{array}$ & $\begin{array}{l}\text { S3 } \\
\text { S2 }\end{array}$ \\
\hline $\begin{array}{ll}- & \mathrm{N} \text {-total }(\%) \\
- & \mathrm{P}_{2} \mathrm{O}_{5} \text { tersedia }(\mathrm{ppm}) \\
- & \mathrm{K}_{2} \mathrm{O} \text { tersedia }(\mathrm{mg} / 100 \mathrm{gr}) \\
\end{array}$ & $\begin{array}{l}\text { N2 } \\
\text { N2 } \\
\text { N2 }\end{array}$ & $\begin{array}{l}\text { N2 } \\
\text { N2 } \\
\text { N2 }\end{array}$ & $\begin{array}{l}\mathrm{N} 2 \\
\mathrm{~N} 2 \\
\mathrm{~N} 2\end{array}$ & $\begin{array}{l}\text { N2 } \\
\text { N2 } \\
\text { N2 }\end{array}$ \\
\hline $\begin{aligned} & \text { Topografi } \\
&- \text { Kemiringan lereng }(\%) \\
&- \text { Ketinggian tempat (mdpl) }\end{aligned}$ & $\begin{array}{l}\text { S3 } \\
\text { S1 }\end{array}$ & $\begin{array}{l}\text { S3 } \\
\text { S1 }\end{array}$ & $\begin{array}{l}\text { S3 } \\
\text { S1 }\end{array}$ & $\begin{array}{l}\text { S3 } \\
\text { S1 }\end{array}$ \\
\hline Klasifikasi Kelas Kesesuaian Lahan & & & & N1 \\
\hline
\end{tabular}

Sumber : Data Primer Olahan 2016

Pada hasil penelitian telah dilakukan teknik matching (mencocokkan) antara karakteristik lahan dengan persyaratan tumbuh tanaman jagung maka suhu, topografi, KTK, $\mathrm{pH}, \mathrm{N}$-total, $\mathrm{P}_{2} \mathrm{O}_{5}, \mathrm{~K}_{2} \mathrm{O}$ tanah tanaman jagung di Kecamatan Binjai Utara berada pada kelas kesesuaian lahan N1 (tidak sesuai untuk saat ini). Beberapa faktor pembatas masih sangat memungkinkan untuk diperbaiki sehingga kelas kesesuaian lahan dapat ditingkatkan. Lahan yang dapat diolah masyarakat meskipun dengan faktor pembatasnya $\mathrm{N}$ total (\%) , $\mathrm{P}_{2} \mathrm{O}_{5}$ tersedia (ppm), $\mathrm{K}_{2} \mathrm{O}$ tersedia (mg/100gr). Untuk mengatasi hal ini dapat ditingkatkan dengan pemberian pupuk pada upaya peningkatan produksi jagung, pemupukan merupakan hal penting dan harus diperhatikan, jenis pupuk yang diberikan pada jagung bisa pupuk organis maupun anorganik.

\section{KESIMPULAN DAN SARAN Kesimpulan}

Berdasarkan pada pembahasan yang telah dijelaskan sebelumnya, maka dapat disimpulkan sebagai berikut :

- Kecamatan Binjai Utara memiliki suhu rata-rata sebesesar $31^{\circ} \mathrm{C}$, Untuk diperbaiki adalah $\mathrm{N}$-Total, $\mathrm{P}_{2} \mathrm{O}_{5}$ dan $\mathrm{K}_{2} \mathrm{O}$. Untuk detail yang lebih lengkap dapat di lihat pada tabel 10. 
instansi yang terkait seperti dinas pertanian. Faktor pembatas yang ditemukan adalah kurangnya semua unsur, sehingga petani tidak cocok untuk menanam jagung pada saat ini.

\section{DAFTAR PUSTAKA}

Anggraini, E. Tikha. 2011. Evaluasi Kesesuaian Untuk Tanaman Kopi di Kecamatan Bulu Kabupaten Temanggung. Skripsi. Jurusan Geografi Fakultas Ilmu Sosial. Semarang: Universitas Negeri Semarang.

Arsyad, Sitanala. 2010 Konservasi Tanah dan Air. Bogor : IPB Press

Departemen Kehutanan. 2013. Pedoman Identifikasi Karakteristik Daerah Aliran Sungai. Jakarta: Departemen Kehutanan

(http://www.dephut.go.id/uploads/ files/ccf8b3ac40f35053b9f20f6b5e 9a878d.pdf) diakses pada Rabu, 15 Juni 2016 jam 12.45 WIB

Elfayetti, E. (2009). Pengaruh Pemberian Kascing dan Pupuk N, P, K Buatan Pada Ultisol Terhadap Sifat Kimia Tanah dan Hasil Tanaman Jagung (Zea Mays L). JURNAL GEOGRAFI, 1(1), 51-56.

Hanafiah, Kemas Ali. 2009. Dasar-dasar Ilmu Tanah. Jakarta : Rajawali Pers http://www.google.co.id/url?sa $=t \&$ $r c t=j \& q=p h \% 20$ tanah\%20dalam $\% 20$ kartasapetra\&sourceository.usu .ac.id\%2Fbitstream,d.bmk, diakses tanggal 17 April 2016

http://allaboutpertanian.blogspot.com/201 2/04/peranan-unsur-kalium-kpadapertanian.html diakses 26 April 2016

Kartasapoetra, A.G dan Mul Mulyani. 2010. Teknologi Konservasi Tanah dan Air. Jakarta: Penerbit Rineka Cipta
Mas'udah Jayanti. 2008. Evaluasi Kesesuaian Lahan Petanian Untuk Tanaman Jagung di Kecamatan Bluto Kabupaten Sumenep.Skripsi. Malang: Jurusan Geografi Universitas Negeri Malang

Purwono,dkk. 2005. Bertanam Jagung Unggul. Bogor:Penebar Swadaya

Rismaneswati. 2012. Evaluasi Kesesuaian Lahan Untuk Tanaman Jagung Pada Beberapa Jenis Tanah Lahan Kering Sulawesi Selatan.Disertasi. Makassar: Program Studi Ilmu Pertanian Program Pasca Sarjana Universita Hasanuddin Makassar

Simanungkalit, N. M. (2011). Evaluasi Kemampuan Lahan dan Penggunaan Lahan Pertanian Di Sub DAS Gotigoti Daerah Aliran Sungai Batangtoru Kabupaten Tapanuli Utara. JURNAL GEOGRAFI, 3(1), 116.

Sitorus, S.R.P. 1985. Evaluasi Sumberdaya Lahan. Bandung: Tarsito

Siswanto. 2006. Evaluasi Sumberdaya Lahan.Surabaya:UPN Press

Sulistiyono, Dwi Abidin. 2010. Evaluasi Kesesuaian Lahan Dan Produktivitas Tanaman Jagung Di DAS Grindulu Hulu Kabupaten Pacitan Dan Ponorogo Tahun 2009.Skripsi. Surabaya:Jurusan Pendidikan IPS Fakultas Keguruan dan Ilmu Pendidikan Universitas Negeri Surabaya

Suparnia. 2013. Evaluasi Kesesuaian Lahan Pada Tanaman Padi Sawah di Kecamatan Stabat Kabupaten Langkat. Skripsi. Jurusan Pendidikan Geografi Fakultas Ilmu Sosial. Medan: Universitas Negeri Medan 